\title{
BMJ Open Social and behavioural factors associated with frailty trajectories in a population-based cohort of older adults
}

Alanna M Chamberlain, ${ }^{1,2}$ Jennifer L St. Sauver, ${ }^{1,2}$ Debra J Jacobson, ${ }^{1,2}$ Sheila M Manemann, ${ }^{1}$ Chun Fan, ${ }^{1}$ Véronique L Roger, ${ }^{1,2,3}$ Barbara P Yawn, ${ }^{4}$ Lila J Finney Rutten ${ }^{1,2}$

To cite: Chamberlain AM, St. Sauver JL, Jacobson DJ, et al. Social and behavioural factors associated with frailty trajectories in a populationbased cohort of older adults. BMJ Open 2016;6:e011410. doi:10.1136/bmjopen-2016011410

- Prepublication history for this paper is available online. To view these files please visit the journal online (http://dx.doi.org/10.1136/ bmjopen-2016-011410).

Received 4 February 2016 Revised 27 April 2016

Accepted 29 April 2016

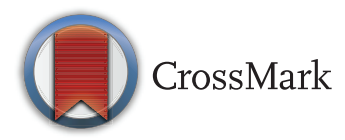

${ }^{1}$ Department of Health Sciences Research, Mayo Clinic, Rochester, Minnesota, USA

${ }^{2}$ Robert D. and Patricia

E. Kern Center for the Science of Health Care Delivery, Mayo Clinic, Rochester, Minnesota, USA ${ }^{3}$ Division of Cardiovascular Diseases, Mayo Clinic, Rochester, Minnesota, USA ${ }^{4}$ Department of Research, Olmsted Medical Center, Rochester, Minnesota, USA

\section{Correspondence to} Dr Alanna M Chamberlain; chamberlain.alanna@mayo. edu

\section{ABSTRACT}

Objective: The goal of this study was to identify distinct frailty trajectories (clusters of individuals following a similar progression of frailty over time) in an ageing population and to determine social and behavioural factors associated with frailty trajectories.

Design: Population-based cohort study.

Setting: Olmsted County, Minnesota.

Participants: Olmsted County, Minnesota residents aged 60-89 in 2005.

Primary outcome measure: Changes in frailty over an 8-year period from 2005 to 2012, measured by constructing a yearly frailty index. Frailty trajectories by decade of age were determined using k-means cluster modelling for longitudinal data.

Results: After adjustment for age and sex, all social and behavioural factors (education, marital status, living arrangements, smoking status and alcohol use) were significantly associated with frailty trajectories in those aged 60-69 and 70-79 years. After further adjustment for baseline frailty, the likelihood of being in the high frailty trajectory was greatest among those reporting concerns from relatives/friends about alcohol consumption (OR (95\% Cl) $2.26(1.19$ to 4.29$)$ ) and those with less than a high school education (OR $(95 \%$ Cl) 1.98 (1.32 to 2.96)) in the 60-69 year olds. In the 70-79 year olds, the largest associations were observed among those with concerns from oneself about alcohol consumption (OR $(95 \% \mathrm{Cl}) 1.92(1.23$ to 3.00$))$, those with less than a high school education $(\mathrm{OR}(95 \% \mathrm{Cl})$ 1.57 (1.12 to 2.22)), and those living with family (vs spouse; $\mathrm{OR}(95 \% \mathrm{Cl}) 1.76$ (1.05 to 2.94)). No factors remained associated with frailty trajectories in the 80-89 year olds after adjustment for baseline frailty.

Conclusions: Social and behavioural factors are associated with frailty, with stronger associations observed in younger ages. Recognition of social and behavioural factors associated with increasing frailty may inform interventions for individuals at risk of worsening frailty, specifically when targeted at younger individuals.

\section{INTRODUCTION}

The ageing of the population has important social and economic implications, including

\section{Strengths and limitations of this study}

- We identified distinct frailty trajectories (clusters of individuals following a similar progression of frailty over time) in an elderly population and found that social and behavioural factors were associated with a higher frailty trajectory over time, but that associations varied across age, with stronger associations in younger ages.

- Importantly, our study found that even after adjustment for baseline frailty level, less than a high school education, non-married marital status, smoking and concerns from family and friends about one's alcohol consumption were associated with being in the high frailty trajectory for those aged 60-79 years, but no factors were associated with frailty trajectories in the 80 89 year olds after adjustment for baseline frailty.

- Social and behavioural factors associated with increasing frailty may offer a way to target interventions for ageing individuals at risk of worsening frailty.

- However, it is unknown whether our findings would be replicated in different populations or if different definitions of frailty were used.

increased utilisation of healthcare resources and related expenditures. ${ }^{1}{ }^{2}$ Notably, although declines in health are generally observed with increasing age, variability across individuals in health status exists at any given age. ${ }^{3}$ It is, therefore, critically important to measure changes in health status as people age and to understand the social and behavioural factors that are associated with such changes over the life course.

Variation in health status can be conceptualised and quantified through measures of frailty, a clinically recognised syndrome characterised by age-associated declines in function across multiple organ systems and physiologic reserve. ${ }^{4-7}$ We and others have previously shown that frailty trajectories are strongly associated with multiple adverse 
outcomes. ${ }^{3} 8-10$ However, the factors that are associated with the development of frailty are unclear. The majority of studies examining the social and behavioural factors that influence frailty are cross-sectional. ${ }^{11-23}$ Few have explored social and behavioural factors that influence changes in frailty over time, ${ }^{24-27}$ and even fewer have assessed factors predicting longitudinal changes in frailty measured at more than two time points. ${ }^{28}{ }^{29}$ Furthermore, inconsistent results emerged from two studies assessing the association of education with changes in frailty over five time points, with lower education associated with worsening trajectories of frailty in a study among older Taiwanese adults, ${ }^{29}$ but not in the Longitudinal Aging Study Amsterdam. ${ }^{28}$ These results underscore the importance of additional studies examining factors associated with changes in frailty over time to inform interventions that might delay or prevent frailty development and progression. Thus, we identified distinct frailty trajectories (clusters of individuals following a similar progression of frailty over time) in an elderly population and examined associations between frailty trajectories and social and behavioural factors known to be associated with health outcomes.

\section{METHODS}

\section{Study population}

This study used the 2005 population of Olmsted County, Minnesota (MN) aged 60-89 ( $\mathrm{n}=16443)$ obtained from the Rochester Epidemiology Project (REP). ${ }^{30-33}$ The REP is a records-linkage system allowing virtually complete capture of medical records data in county residents. Since Olmsted County is relatively isolated from other urban centres and only a few providers deliver most healthcare to local residents, the capture of nearly all healthcare-related events occurring in Olmsted County residents is possible. Importantly, demographic and ethnic characteristics of Olmsted County are representative of the state of $\mathrm{MN}$ and the Midwest region of the USA, and age- and sex-specific mortality rates are similar to national data. ${ }^{31}$ This study was approved by the Mayo Clinic and Olmsted Medical Center Institutional Review Boards.

\section{Calculation of the frailty index}

Frailty was calculated using the frailty index, which measures variation in health status based on an accumulation of deficits (impairments, disabilities, diseases) by quantifying the amount of frailty in a given individual as the proportion of deficits present in that individual. ${ }^{34} 35$ This index has been shown to perform well at predicting death $^{22} 343637$ and can be constructed using deficits available in the electronic medical record..$^{38}$

A frailty index was calculated using 32 deficits, as described previously. ${ }^{9}$ Briefly, body mass index (BMI) was obtained electronically from one of the institutions and 14 self-reported activities of daily living (ADLs) were obtained from a questionnaire administered on at least a yearly basis to patients seen at one of the institutions. Comorbidities were obtained electronically from all providers in the REP. We chose a list of comorbidities identified by the US Department of Health and Human Services (US-DHHS) ${ }^{39} 40$ and included the 17 (out of 20) conditions with $>1 \%$ prevalence in the population. More extensive details including the code sets for these conditions were reported elsewhere. ${ }^{41}$

All variables in the frailty index were given 1 point when present and 0 points when not present, with the exception of BMI (18.5 to $<25,0$ points; 25 to $<30,0.5$ points; $<18.5$ or $\geq 30,1$ point) and the ADL, climbing two flights of stairs without rest (yes, with no difficulty, 0 points; yes, with difficulty, 0.5 points; no, 1 point). The frailty index was calculated as the cumulative points divided by 32 (range of $0-1$ ). The index was calculated only if three or fewer items were missing, adjusting the denominator accordingly. Repeated measures of frailty index were calculated for each year through 2012 (one index per year). Linear interpolation was used to impute missing BMI values between the first and last available BMI. Once a comorbidity was identified, this was carried forward for all subsequent frailty index measures. More details on the rules for calculating the frailty index have been reported previously. ${ }^{9}$ Finally, for each patient, the year of the first available frailty index was considered the baseline frailty index measure.

\section{Ascertainment of social and behavioural factors}

Social and behavioural factors were self-reported and obtained via the same questionnaire as the ADLs, which is routinely administered to all patients at their healthcare visits on at least a yearly basis at one of the institutions. The social and behavioural factors included education level, marital status, living environment and arrangement, and questions pertaining to smoking status and alcohol use.

\section{Statistical analysis}

Analyses were performed using SAS statistical software, V.9.3 (SAS Institute Inc, Cary, North Carolina, USA) and R, V.3.0.2 ( $\mathrm{R}$ Foundation for Statistical Computing, Vienna, Austria). Patients with at least 3 years of frailty measures were retained for analysis $(n=12270)$. The frailty index and prevalence of social factors differed across age. Thus, we stratified our cohort into three groups based on age in 2005: 60-69, 70-79 and 80-89 years. The baseline age defined the age groups and the same groupings were used across follow-up although patients could have aged into another age group during follow-up. $\mathrm{K}$ means cluster modelling for longitudinal data (KmL, R, V.3.0.2 (R Foundation for Statistical Computing, Vienna, Austria)), was used to identify distinct, homogeneous clusters of frailty index trajectories within each age group. ${ }^{42} \mathrm{KmL}$ is a non-parametric hillclimbing algorithm, and does not impose assumptions regarding the parameterisation within the clusters or the shape of the trajectories. The optimum number of 
clusters in each age group was determined using the Calinksi and Harabatz criterion. ${ }^{42}$ The optimum number of clusters was three for the 60-69 year olds and two for both the 70-79 and 80-89 year olds. For the 60-69 year olds, the proportional odds assumption to fit an ordinal logistic regression model was not met; therefore, model fit was assessed with two trajectories. The proportion of patients in each trajectory that had a predicted probability of $>80 \%$ of being in that trajectory was $98 \%$ for the low trajectory and $85 \%$ for the high trajectory when two trajectories were used. Therefore, while the best fit was for the model with three trajectories, the majority of patients fit in the two trajectories with high probability. Thus, for consistency, we remodelled the frailty trajectories in the 60-69 year olds using only two trajectories.

Within each age group, characteristics at baseline (including comorbidities, ADLs and social factors) were compared for the low vs high frailty trajectories using $\chi^{2}$ tests. Logistic regression was used to determine the associations of social and behavioural factors with baseline frailty (defining high baseline frailty as a frailty index of 0.20 or higher, which corresponds to the 75th percentile of the distribution of the frailty index) and frailty trajectories (modelling the odds of being in the high frailty trajectory). Multivariable models were used to adjust for age and sex. Additional adjustment for baseline frailty index was included in the frailty trajectory modelling. Finally, within each age group, interactions between each social and behavioural variable with sex were tested; no significant differences between men and women were observed, and thus, no stratified results by sex are provided.

\section{RESULTS}

Among the 16443 residents of Olmsted County, MN aged 60-89 in 2005, $12270(74.6 \%)$ had at least 3 years of frailty measures between 2005 and 2012 and were retained for analysis (figure 1). Of those retained, the median number of years of frailty measures was 5 . Of those excluded, $17 \%$ had died within 3 years of follow-up. Of the 12270 patients retained, $44.5 \%$ were male, $49.3 \%$ were aged $60-69$ and $15.6 \%$ were aged $80-89$ at baseline, and $18 \%$ died during follow-up. The demographics for those with at least 3 years of frailty measures were similar to the entire population (median age: 70.2 vs 70.5 ; male: $44.5 \%$ vs $45.0 \%$; non-white race: $3.7 \%$ vs $5.0 \%$ ). For all age groups, the frailty index increased over time for each trajectory (figure 2). The proportion of patients in the high trajectory increased with age; $29 \%, 34 \%$ and $45 \%$ of patients aged $60-69$, $70-79$ and 80-89, respectively, were in the high trajectory. For the high frailty trajectory, the mean frailty index increased from 0.21 to 0.32 in 60-69 year olds, 0.24 to 0.41 for $70-79$ year olds and 0.28 to 0.49 for 80 89 year olds, which equates to an accumulation of an additional 4, 5 and 7 deficits, respectively, over 8 years.

Within each age group, a higher proportion of each comorbidity and ADL was observed at baseline for those in the high trajectory compared with the low trajectory (table 1). For the 60-69 and 70-79 year olds, those in the high trajectory had a higher prevalence of ever smoking and concerns with alcohol consumption, lower educational attainment, were less likely to be married or live with a spouse/domestic partner, but were more likely to have assistance for home care from family and/ or friends than those in the low trajectory (table 2). Similar differences were observed among the 80-89 year olds, with the exception of smoking status and alcohol consumption which were similar between those in the high and low frailty trajectories.

\section{Baseline frailty}

After adjustment for age and sex, all social and behavioural factors were predictive of having a high baseline
Figure 1 Selection of the final analytic sample, including a distribution of the number of years of frailty measures for those excluded and those retained for analysis.

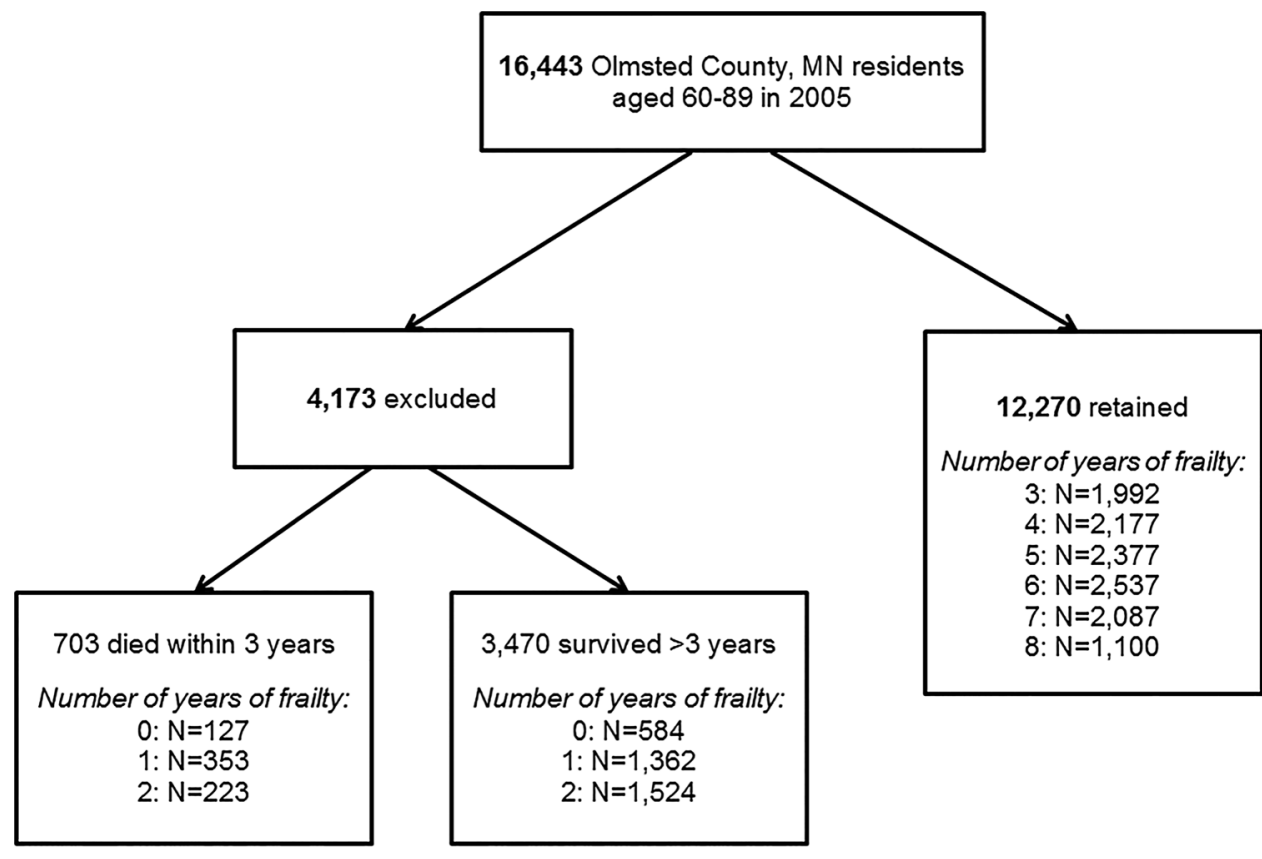



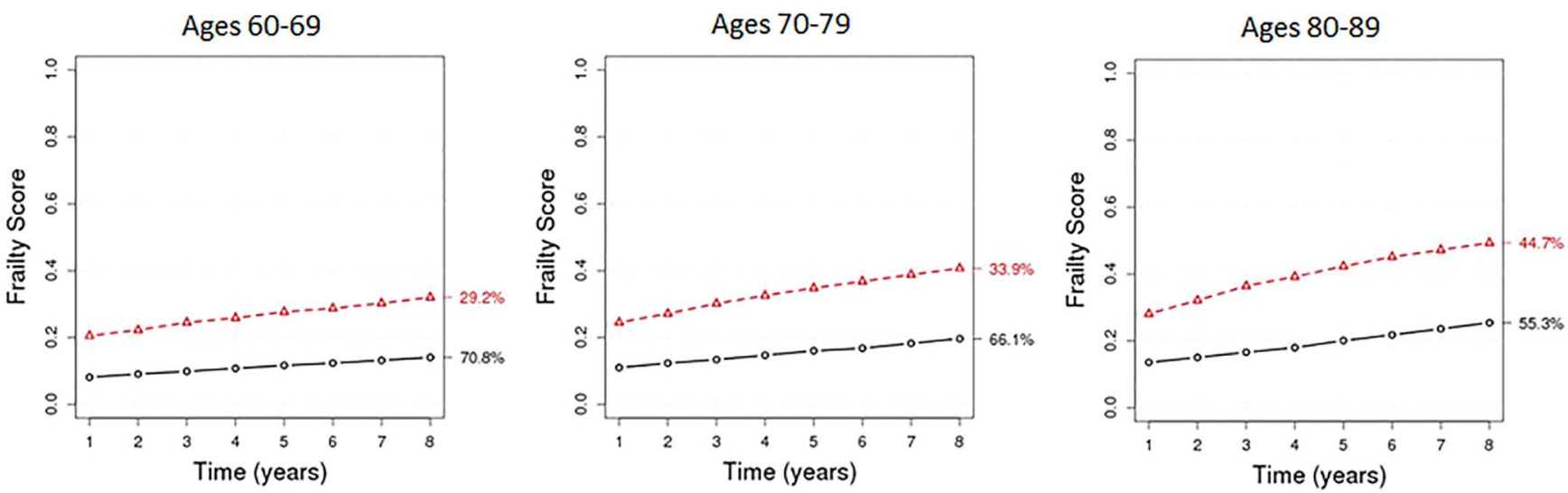

Figure 2 Frailty trajectory plots in the 60-69, 70-79 and 80-89 year old age groups. The black line indicates the low trajectory and the red line indicates the high trajectory. The percentage next to each trajectory indicates the proportion of individuals in that trajectory.

frailty index (defined as an index of 0.20 or higher) in the 60-69 and 70-79 year olds (table 3 ). The strongest association was observed for education, with a fivefold increased odds in the 60-69 year olds (OR (95\% CI) 4.98 (3.72 to 6.67)) and a threefold increased odds (OR (95\% CI) 2.94 (2.32 to 3.73)) in the 70-79 year olds of having a high baseline frailty index for those with less than high school vs 4-year college degree or higher. In addition, more than a twofold increased odds of having a high frailty index at baseline was observed for those whose relatives or friends are concerned about their alcohol consumption, who are non-married, and who live with family (compared with living with a spouse) in the 60-69 year olds, and concerns from oneself or relatives/friends about alcohol consumption in the 70-79 year olds. In the 80-89 year olds, concerns about alcohol consumption from relatives/friends had the strongest association with having a high baseline frailty index (OR (95\% CI) 4.20 (1.15 to 15.41)), whereas a twofold increased odds (OR (95\% CI) 1.97 (1.48 to 2.63)) was observed for those with less than a high school education.

\section{Frailty trajectories}

In the 60-69 year olds, smoking status, concerns from relatives/friends about alcohol consumption, less than high school education and non-married marital status were associated with being in the high frailty trajectory after adjustment for age, sex and baseline frailty (table 4). Concerns from relatives/friends about alcohol consumption (OR (95\% CI) 2.26 (1.19 to 4.29)) and having less than a high school education (OR (95\% CI) 1.98 (1.32 to 2.96)) were most strongly associated with being in the high frailty trajectory. For the 70-79 year olds, smoking, concerns from oneself about alcohol consumption, less than high school education, non-married marital status and living alone or with family were associated with being in the high frailty trajectory. More than a 50\% increased odds of being in the high frailty trajectory was observed among those reporting concerns from oneself about alcohol consumption (OR (95\% CI) 1.92 (1.23 to 3.00)), less than high school education (OR (95\% CI) 1.57 (1.12 to 2.22)) and living with family (vs spouse; OR (95\% CI) 1.76 (1.05 to 2.94)). However, none of the social and behavioural factors remained associated with frailty trajectories in the 80-89 year olds after adjustment for age, sex and baseline frailty index.

\section{DISCUSSION}

In this elderly population, social and behavioural factors were associated with frailty, but differences were observed across ages, with stronger associations in younger ages. Importantly, our study found that even after adjustment for baseline frailty level, several social and behavioural factors were associated with being in a higher frailty trajectory over time. Less than a high school education, non-married marital status, smoking and concerns from family and friends about one's alcohol consumption were associated not only with baseline frailty, but with being in the high frailty trajectory for 60-69 and 70-79 year olds, even after adjustment for baseline frailty.

Measures of social position, such as education, are the most widely studied in relation to frailty, and are theorised to influence frailty indirectly by interfering with lifestyle behaviours and quality of life. ${ }^{43}$ Despite differences in the definitions of frailty used across studies, most, ${ }^{11} 12 \quad 15{ }^{19-21} \quad{ }^{23}$ but not all ${ }^{13} 16{ }^{17}$ cross-sectional studies reported an inverse association between years of education and frailty. Other studies have indicated that being non-married or living alone are associated with frailty. ${ }^{12} \quad 14 \quad 15 \quad 17 \quad 23$ Our study confirms these crosssectional associations, but attempts to more precisely delineate the relationship between social factors and frailty by modelling trajectories of frailty and determining whether associations persist after adjustment for baseline levels of frailty. Some prior studies have reported that lower education was associated with 
Table 1 Differences across the frailty trajectories in comorbidities and activities of daily living present at baseline

\begin{tabular}{|c|c|c|c|c|c|c|}
\hline & \multicolumn{2}{|c|}{$60-69$ year olds $(\mathrm{N}=6045)$} & \multicolumn{2}{|c|}{$70-79$ year olds $(\mathrm{N}=4314)$} & \multicolumn{2}{|c|}{$80-89$ year olds $(\mathrm{N}=1911)$} \\
\hline & $\begin{array}{l}\text { Low } \\
\text { trajectory }\end{array}$ & $\begin{array}{l}\text { High } \\
\text { trajectory }\end{array}$ & $\begin{array}{l}\text { Low } \\
\text { trajectory }\end{array}$ & $\begin{array}{l}\text { High } \\
\text { trajectory }\end{array}$ & $\begin{array}{l}\text { Low } \\
\text { trajectory }\end{array}$ & $\begin{array}{l}\text { High } \\
\text { trajectory }\end{array}$ \\
\hline \multicolumn{7}{|l|}{ Comorbidities } \\
\hline \multicolumn{7}{|l|}{ Body mass index, $\mathrm{kg} / \mathrm{m}^{2}$} \\
\hline$<18.5$ & $25(0.6)$ & $16(1.0)$ & $25(0.9)$ & $12(0.8)$ & $19(1.9)$ & $13(1.6)$ \\
\hline 18.5 to $<25$ & $1097(27.5)$ & $194(11.6)$ & $769(28.7)$ & $232(16.5)$ & $385(38.8)$ & $212(26.0)$ \\
\hline 25 to $<30$ & $1718(43.0)$ & $467(27.8)$ & $1230(45.9)$ & $446(31.7)$ & $424(42.8)$ & $306(37.6)$ \\
\hline$\geq 30$ & $1154(28.9)$ & $1002(59.7)$ & $655(24.5)$ & $717(51.0)$ & $163(16.5)$ & $283(34.8)$ \\
\hline Hypertension & $2512(58.7)$ & $1618(91.7)$ & 2144 (75.2) & $1380(94.5)$ & 887 (83.9) & $815(95.4)$ \\
\hline Congestive heart failure & $61(1.4)$ & $320(18.1)$ & $160(5.6)$ & $514(35.2)$ & $174(16.5)$ & 443 (51.9) \\
\hline Coronary artery disease & $724(16.9)$ & $983(55.7)$ & $892(31.3)$ & $964(66.0)$ & 373 (35.3) & $545(63.8)$ \\
\hline Cardiac arrhythmia & $1130(26.4)$ & $1101(62.4)$ & $1364(47.8)$ & $1156(79.1)$ & $670(63.4)$ & $724(84.8)$ \\
\hline Hyperlipidaemia & 3067 (71.7) & $1613(91.4)$ & $2210(77.5)$ & 1300 (89.0) & $737(69.7)^{\star}$ & $646(75.6)^{*}$ \\
\hline Stroke & $237(5.5)$ & 387 (21.9) & 368 (12.9) & 452 (30.9) & $171(16.2)$ & $303(35.5)$ \\
\hline Arthritis & 1949 (45.5) & 1259 (71.3) & 1624 (56.9) & 1134 (77.6) & $663(62.7)$ & $663(77.6)$ \\
\hline Asthma & $253(5.9)$ & 301 (17.1) & $175(6.1)$ & $220(15.1)$ & $64(6.1)$ & $114(13.4)$ \\
\hline Cancer & $1612(37.7)$ & $860(48.7)$ & $1437(50.4)$ & $878(60.1)$ & $605(57.2) \dagger$ & $537(62.9) \dagger$ \\
\hline Chronic kidney disease & $226(5.3)$ & $526(29.8)$ & 337 (11.8) & $596(40.8)$ & $242(22.9)$ & $431(50.5)$ \\
\hline COPD & $286(6.7)$ & $534(30.3)$ & $329(11.5)$ & $525(35.9)$ & $138(13.1)$ & 279 (32.7) \\
\hline Dementia & $69(1.6)$ & $156(8.8)$ & $197(6.9)$ & 326 (22.3) & $135(12.8)$ & $325(38.1)$ \\
\hline Depression & $559(13.1)$ & $676(38.3)$ & $382(13.4)$ & $568(38.9)$ & 168 (15.9) & $360(42.2)$ \\
\hline Diabetes & 1765 (41.2) & 1225 (69.4) & 1292 (45.3) & $955(65.4)$ & 396 (37.5) & $416(48.7)$ \\
\hline Osteoporosis & 565 (13.2) & 326 (18.5) & $688(24.1)$ & $463(31.7)$ & $375(35.5)^{\star}$ & $354(41.5)^{*}$ \\
\hline Schizophrenia & $18(0.4)$ & $81(4.6)$ & $28(1.0)$ & $113(7.7)$ & $35(3.3)$ & $117(13.7)$ \\
\hline Substance abuse disorders $\ddagger$ & 69 (1.6) & $142(8.1)$ & $21(0.7)$ & $87(6.0)$ & 9 (0.9)† & $17(2.0) \dagger$ \\
\hline \multicolumn{7}{|l|}{ Activities of daily living } \\
\hline Preparing meals & $34(0.8)$ & $126(7.1)$ & $33(1.2)$ & $160(11.0)$ & $26(2.5)$ & $168(20.5)$ \\
\hline Feeding yourself & $8(0.2)$ & $27(1.5)$ & $7(0.3)$ & $28(1.9)$ & $7(0.7)^{*}$ & $18(2.2)^{*}$ \\
\hline Dressing yourself & $23(0.5)$ & $94(5.3)$ & $19(0.7)$ & $99(6.8)$ & $13(1.3)$ & $77(9.4)$ \\
\hline Using the toilet & $10(0.2)$ & $58(3.3)$ & 7 (0.3) & $55(3.8)$ & $9(0.9)$ & $42(5.1)$ \\
\hline Housekeeping & $40(0.9)$ & $241(13.7)$ & $49(1.7)$ & $272(18.6)$ & $63(6.1)$ & $254(31.0)$ \\
\hline Climbing stairs & $119(2.8)$ & 474 (26.9) & $162(5.7)$ & $544(37.2)$ & $102(9.9)$ & $393(48.0)$ \\
\hline Bathing & $15(0.4)$ & $120(6.8)$ & $9(0.3)$ & $108(7.4)$ & $16(1.6)$ & 125 (15.3) \\
\hline Walking & $71(1.7)$ & $306(17.3)$ & $95(3.3)$ & $405(27.7)$ & $81(7.9)$ & $298(36.4)$ \\
\hline Using transportation & $15(0.4)$ & $104(5.9)$ & $20(0.7)$ & $134(9.2)$ & $31(3.0)$ & 138 (16.9) \\
\hline Getting in and out of bed & $379(9.4)$ & $329(19.7)$ & $285(10.6)$ & $279(20.1)$ & $137(14.3)$ & $166(21.3)$ \\
\hline Managing medications & $12(0.3)$ & $105(6.0)$ & $21(0.7)$ & $133(9.1)$ & $14(1.4)$ & 149 (18.2) \\
\hline $\begin{array}{l}\text { Depend on assistive devices } \\
\text { (walker, cane, etc) or other } \\
\text { people to perform ADLs }\end{array}$ & $65(1.5)$ & $285(16.6)$ & 110 (3.9) & $434(30.7)$ & $130(13.1)$ & $463(58.0)$ \\
\hline $\begin{array}{l}\text { Dependent on a device for } \\
\text { normal breathing }\end{array}$ & $89(2.2)$ & $244(15.0)$ & $63(2.3)$ & $139(10.4)$ & $25(2.6)$ & $66(8.9)$ \\
\hline \multicolumn{7}{|c|}{ Climb 2 flights of stairs without rest } \\
\hline No, can't do at all & $31(0.8)$ & $261(15.7)$ & $47(1.7)$ & $322(23.7)$ & $57(6.0)$ & $306(42.0)$ \\
\hline Yes, with difficulty & $519(12.5)$ & $601(36.1)$ & $572(21.0)$ & $623(45.9)$ & $276(29.0)$ & 277 (38.0) \\
\hline Yes with no difficulty & 3581 (86.4) & $778(46.8)$ & 2077 (76.4) & $382(28.2)$ & $602(63.4)$ & $127(17.4)$ \\
\hline Unknown & $12(0.3)$ & $23(1.4)$ & $24(0.9)$ & $30(2.2)$ & $15(1.6)$ & $19(2.6)$ \\
\hline $\begin{array}{l}\text { alues are } N(\%) \text {. All } p \text { values are } \\
\text { Value }<0.01 . \\
\text { Value }<0.05 \text {. } \\
\text { Drug and alcohol substance abu }\end{array}$ & less otherv & dicated. & & & & \\
\hline
\end{tabular}

worsening of frailty between two ${ }^{24-26}$ or five time points; ${ }^{29}$ however, one study reported that the increased rate of frailty over five points in time did not differ by education level. ${ }^{28}$ Only one study assessed associations of marital status with changes in frailty and found that marital status was not significantly related to changes in frailty over 2 years. $^{25}$ Importantly, only two ${ }^{25} 26$ of the prior studies adjusted for baseline levels of frailty. Our study found that education and marital status were associated with frailty trajectories in all ages, but remained 
Table 2 Differences across frailty trajectories in social and behavioural factors at baseline

\begin{tabular}{|c|c|c|c|c|c|c|}
\hline & \multicolumn{2}{|c|}{ 60-69 year olds } & \multicolumn{2}{|c|}{ 70-79 year olds } & \multicolumn{2}{|c|}{ 80-89 year olds } \\
\hline & $\begin{array}{l}\text { Low } \\
\text { trajectory }\end{array}$ & $\begin{array}{l}\text { High } \\
\text { trajectory }\end{array}$ & $\begin{array}{l}\text { Low } \\
\text { trajectory }\end{array}$ & $\begin{array}{l}\text { High } \\
\text { trajectory }\end{array}$ & $\begin{array}{l}\text { Low } \\
\text { trajectory }\end{array}$ & $\begin{array}{l}\text { High } \\
\text { trajectory }\end{array}$ \\
\hline Ever smoking status & $2091(50.4)$ & $1052(62.4)$ & $1358(49.6)$ & $809(58.1)$ & $436(43.3)^{\star}$ & $380(46.6)^{\star}$ \\
\hline $\begin{array}{l}\text { Ever felt the need to cut down on } \\
\text { alcohol consumption }\end{array}$ & $191(4.6)$ & $127(7.4)$ & $99(3.5)$ & $98(6.9)$ & $25(2.5)^{*}$ & $21(2.6)^{\star}$ \\
\hline $\begin{array}{l}\text { Relatives/friends worry or complain } \\
\text { about your alcohol consumption } \\
\text { Education }\end{array}$ & $40(1.0)$ & $47(2.8)$ & $16(0.6)$ & $23(1.6)$ & $6(0.6)^{*}$ & $7(0.9)^{\star}$ \\
\hline Less than high school & $138(3.4)$ & $155(9.4)$ & $211(7.8)$ & $234(17.0)$ & $164(16.8)$ & $187(23.4)$ \\
\hline High school/GED/some college & $2390(58.1)$ & $1077(65.1)$ & $1630(60.1)$ & $843(61.1)$ & $558(57.0)$ & $448(56.2)$ \\
\hline 4-year college/postgraduate & $1585(38.5)$ & $422(25.5)$ & $872(32.1)$ & $303(21.9)$ & $257(26.2)$ & $163(20.4)$ \\
\hline $\begin{array}{l}\text { Married/committed relationship } \\
\text { With whom you live }\end{array}$ & $3493(82.7)$ & $1255(72.0)$ & $2104(74.3)$ & 897 (62.2) & $567(54.6)$ & $373(44.6)$ \\
\hline Spouse/domestic partner & $3443(81.5)$ & $1221(70.6)$ & 2050 (72.8) & $884(61.6)$ & 550 (53.2) & $351(42.2)$ \\
\hline Family & 147 (3.5) & $106(6.1)$ & $90(3.2)$ & $75(5.2)$ & $50(4.8)$ & $53(6.4)$ \\
\hline Alone & 575 (13.6) & 332 (19.2) & $627(22.3)$ & $425(29.6)$ & $400(38.7)$ & $376(45.2)$ \\
\hline Other & 60 (1.4) & $70(4.1)$ & $49(1.7)$ & 51 (3.6) & 34 (3.3) & $52(6.2)$ \\
\hline $\begin{array}{l}\text { Have assistance for home care } \\
\text { from family, friends or others, if } \\
\text { needed }\end{array}$ & $2559(62.1)$ & 1165 (68.3) & 1720 (62.2) & $1001(71.3)$ & 677 (66.6) & $627(77.7)$ \\
\hline
\end{tabular}

significant after adjustment for baseline frailty in the 6069 and 70-79 year olds. Furthermore, our study is the first to report that living alone or with family (compared with living with a spouse) is associated with longitudinal changes in frailty, with an increased risk of being in the high frailty trajectory in all age groups. However, the associations persisted only among the 70-79 year olds once we adjusted for baseline frailty. It should be noted, however, that living with family may be a marker of increasing frailty and patients may move in with family because they are becoming frail.

The influence of behavioural factors, such as smoking and alcohol use, on frailty is unclear. Cross-sectional studies have reported both lower ${ }^{12}$ and higher $^{23}$ prevalence of current smoking among those with frailty, as well as no difference in smoking between those with and without frailty. ${ }^{17}{ }^{20}$ In contrast, the prevalence of current drinking ${ }^{12} 17$ and heavy drinking $^{23}$ was consistently lower among those with frailty. Results were also mixed among longitudinal studies, with null associations of smoking with changes in frailty in one study, ${ }^{27}$ but a 1.16 -fold increased odds of worsening frailty among smokers in another study. ${ }^{26}$ Finally, greater alcohol consumption was associated with lower risk of frailty worsening over 2 years of follow-up. ${ }^{26}$ In our study, ever smoking and concerns about alcohol consumption were associated with the high frailty trajectory, and associations remained significant after adjustment for baseline frailty in the 60-69 and 70-79 year olds. Although our questions about alcohol consumption did not specifically quantify the amount of drinking, our questions about alcohol likely identified individuals with excessive alcohol consumption and alcoholism, which may explain why our results conflict with previous literature.

An interesting observation of our study is that in the 80-89 year olds, while social and behavioural factors influence baseline frailty, these factors are not associated with changes in frailty over time after adjusting for baseline frailty. Possible explanations include a survival effect, whereby those with poor education and the heaviest smokers and drinkers, for example, have died before reaching this age group. Also, this group experienced the highest levels of frailty at baseline; it is possible that social and behavioural factors may not influence changes in frailty over time once a certain level of frailty is reached. Thus, interventions to either halt the progression of frailty or improve frailty may be best targeted at younger individuals.

\section{Limitations and strengths}

Potential limitations of our study include the choice of our frailty metric. There are different ways to measure frailty and our results may have differed if we used a different definition of frailty. For example, the frailty phenotype $^{15}$ incorporates physical assessments, but with our large sample size, we were unable to implement a measure of frailty that requires in-person physical assessments. Thus, we relied solely on administrative data to construct the frailty index and possible inaccuracies with these data may have affected our results. Furthermore, additional conditions that may contribute to frailty were not available in our electronic medical record. However, the frailty index is optimised when 30-40 different 
Table 3 Multivariate predictors of baseline frailty, defining high baseline frailty as a frailty index of 0.20 or higher

\begin{tabular}{|c|c|c|c|c|}
\hline & \multicolumn{2}{|l|}{ Unadjusted } & \multicolumn{2}{|l|}{ Multivariate $^{\star}$} \\
\hline & $\begin{array}{l}\text { Low baseline } \\
\text { frailty }\end{array}$ & $\begin{array}{l}\text { High baseline } \\
\text { frailty }\end{array}$ & $\begin{array}{l}\text { Low baseline } \\
\text { frailty }\end{array}$ & $\begin{array}{l}\text { High baseline } \\
\text { frailty }\end{array}$ \\
\hline \multicolumn{5}{|l|}{ 60-69 year olds } \\
\hline Ever smokers & 1.00 (ref) & $1.64(1.41$ to 1.91$) \dagger$ & 1.00 (ref) & $1.75(1.50$ to 2.05$) \dagger$ \\
\hline $\begin{array}{l}\text { Ever felt the need to cut down on alcohol } \\
\text { consumption }\end{array}$ & 1.00 (ref) & $1.70(1.29$ to 2.24$) \dagger$ & 1.00 (ref) & $1.80(1.36$ to 2.38$) \dagger$ \\
\hline $\begin{array}{l}\text { Relatives/friends worry or complain about your } \\
\text { alcohol consumption }\end{array}$ & 1.00 (ref) & $2.44(1.52$ to 3.90$) \dagger$ & 1.00 (ref) & $2.60(1.62$ to 4.17$) \dagger$ \\
\hline \multicolumn{5}{|l|}{ Education (vs 4-year college/postgraduate studies) } \\
\hline Less than high school & 1.00 (ref) & $5.11(3.82$ to 6.83$) \dagger$ & 1.00 (ref) & $4.98(3.72$ to 6.67$) \dagger$ \\
\hline High school graduate or GED/some college & 1.00 (ref) & $2.03(1.70$ to 2.44$) \dagger$ & 1.00 (ref) & $1.97(1.64$ to 2.37$) \dagger$ \\
\hline Non-married vs married/committed relationship & 1.00 (ref) & $2.49(2.13$ to 2.91$) \dagger$ & 1.00 (ref) & 2.49 (2.12 to 2.93$) \dagger$ \\
\hline \multicolumn{5}{|c|}{ With whom you live (vs spouse/domestic partner) } \\
\hline Family & 1.00 (ref) & $2.64(1.97$ to 3.52$) \dagger$ & 1.00 (ref) & $2.73(2.04$ to 3.65$) \dagger$ \\
\hline Alone & 1.00 (ref) & $1.96(1.64$ to 2.35$) \dagger$ & 1.00 (ref) & $1.93(1.60$ to 2.32$) \dagger$ \\
\hline $\begin{array}{l}\text { Have assistance for home care from family, } \\
\text { friends or others, if needed (no vs yes) }\end{array}$ & 1.00 (ref) & $0.58(0.50$ to 0.69$) \dagger$ & 1.00 (ref) & $0.59(0.50$ to 0.69$) \dagger$ \\
\hline \multicolumn{5}{|l|}{$70-79$ year olds } \\
\hline Ever smokers & 1.00 (ref) & $1.19(1.04$ to 1.36$) \S$ & 1.00 (ref) & 1.25 (1.08 to 1.44$) \ddagger$ \\
\hline $\begin{array}{l}\text { Ever felt the need to cut down on alcohol } \\
\text { consumption }\end{array}$ & 1.00 (ref) & $1.92(1.43$ to 2.56$) \dagger$ & 1.00 (ref) & $2.08(1.54$ to 2.80$) \dagger$ \\
\hline $\begin{array}{l}\text { Relatives/friends worry or complain about your } \\
\text { alcohol consumption }\end{array}$ & 1.00 (ref) & $2.43(1.29$ to 4.57$) \dagger$ & 1.00 (ref) & $2.64(1.39$ to 5.02$) \dagger$ \\
\hline \multicolumn{5}{|l|}{ Education (vs 4-year college/postgraduate studies) } \\
\hline Less than high school & 1.00 (ref) & $3.20(2.53$ to 4.04$) \dagger$ & 1.00 (ref) & $2.94(2.32$ to 3.73$) \dagger$ \\
\hline High school graduate or GED/some college & 1.00 (ref) & $1.50(1.27$ to 1.77$) \S$ & 1.00 (ref) & $1.45(1.23$ to 1.72$) \S$ \\
\hline Non-married vs married/committed relationship & 1.00 (ref) & $1.70(1.48$ to 1.96$) \dagger$ & 1.00 (ref) & $1.61(1.38$ to 1.87$) \dagger$ \\
\hline \multicolumn{5}{|c|}{ With whom you live (vs spouse/domestic partner) } \\
\hline Family & 1.00 (ref) & $1.77(1.28$ to 2.45$) \dagger$ & 1.00 (ref) & $1.72(1.23$ to 2.39$) \ddagger$ \\
\hline Alone & 1.00 (ref) & $1.42(1.22$ to 1.65$) \dagger$ & 1.00 (ref) & $1.31(1.11$ to 1.54$) \ddagger$ \\
\hline $\begin{array}{l}\text { Have assistance for home care from family, } \\
\text { friends or others, if needed (no vs yes) } \\
80-89 \text { year olds }\end{array}$ & 1.00 (ref) & $0.68(0.59$ to 0.79$) \dagger$ & 1.00 (ref) & $0.68(0.59$ to 0.79$) \dagger$ \\
\hline Ever smokers & 1.00 (ref) & $1.21(1.00$ to 1.45$) \S$ & 1.00 (ref) & $1.28(1.06$ to 1.56$) \S$ \\
\hline $\begin{array}{l}\text { Ever felt the need to cut down on alcohol } \\
\text { consumption }\end{array}$ & 1.00 (ref) & $1.52(0.84$ to 2.74$)$ & 1.00 (ref) & $1.66(0.91$ to 3.03$)$ \\
\hline $\begin{array}{l}\text { Relatives/friends worry or complain about your } \\
\text { alcohol consumption }\end{array}$ & 1.00 (ref) & $3.88(1.07$ to 14.15$) \S$ & 1.00 (ref) & $4.20(1.15$ to 15.41$) \S$ \\
\hline \multicolumn{5}{|l|}{ Education (vs 4-year college/postgraduate studies) } \\
\hline Less than high school & 1.00 (ref) & $1.98(1.49$ to 2.65$) \dagger$ & 1.00 (ref) & $1.97(1.48$ to 2.63$) \dagger$ \\
\hline High school graduate or GED/some college & 1.00 (ref) & $1.22(0.97$ to 1.54$)$ & 1.00 (ref) & $1.22(0.97$ to 1.54$)$ \\
\hline Non-married vs married/committed relationship & 1.00 (ref) & $1.45(1.21$ to 1.74$) \dagger$ & 1.00 (ref) & $1.53(1.24$ to 1.88$) \dagger$ \\
\hline \multicolumn{5}{|c|}{ With whom you live (vs spouse/domestic partner) } \\
\hline Family & 1.00 (ref) & 1.55 (1.03 to 2.33$) \S$ & 1.00 (ref) & $1.58(1.04$ to 2.38$) \S$ \\
\hline Alone & 1.00 (ref) & $1.31(1.09$ to 1.59$) \ddagger$ & 1.00 (ref) & $1.32(1.07$ to 1.63$) \ddagger$ \\
\hline $\begin{array}{l}\text { Have assistance for home care from family, } \\
\text { friends or others, if needed (no vs yes) }\end{array}$ & 1.00 (ref) & $0.57(0.46$ to 0.70$) \dagger$ & 1.00 (ref) & $0.58(0.47$ to 0.72$) \dagger$ \\
\hline \multicolumn{5}{|l|}{$\begin{array}{l}\text { *Multivariate associations are adjusted for age and sex. } \\
\text { tp Value }<0.001 \\
\neq p \text { Value }<0.01 \\
\text { \$p Value }<0.05 \text {. } \\
\text { GED, General Educational Development. }\end{array}$} \\
\hline
\end{tabular}

variables are used; ${ }^{35}$ thus, the addition of variables beyond the 32 included in our index may not have added benefit. Second, we required at least 3 years of frailty index to calculate a frailty trajectory. This resulted in deleting approximately one-quarter of the population from our analysis; however, those included in our study were similar to the entire Olmsted County population aged 60-89. Third, there were a limited number of social factors available from the questionnaire; some potentially important social factors (eg, income) were 
Table 4 Univariate and multivariate predictors of frailty trajectories

\begin{tabular}{|c|c|c|c|c|c|c|}
\hline & \multicolumn{2}{|l|}{ Unadjusted } & \multicolumn{2}{|c|}{ Multivariate $^{\star}$} & \multicolumn{2}{|c|}{ Multivariate† } \\
\hline & $\begin{array}{l}\text { Low } \\
\text { trajectory }\end{array}$ & High trajectory & $\begin{array}{l}\text { Low } \\
\text { trajectory }\end{array}$ & High trajectory & $\begin{array}{l}\text { Low } \\
\text { trajectory }\end{array}$ & High trajectory \\
\hline \multicolumn{7}{|l|}{$60-69$ year olds } \\
\hline Ever felt the need to cut down on alcohol consumption & 1.00 (ref) & $1.67(1.33$ to 2.11$) \ddagger$ & 1.00 (ref) & $1.66(1.31$ to 2.09$) \ddagger$ & 1.00 (ref) & $1.42(0.98$ to 2.04$)$ \\
\hline $\begin{array}{l}\text { Relatives/friends worry or complain about your alcohol } \\
\text { consumption }\end{array}$ & 1.00 (ref) & $2.92(1.91$ to 4.48$) \ddagger$ & 1.00 (ref) & $2.90(1.89$ to 4.46$) \ddagger$ & 1.00 (ref) & 2.26 (1.19 to 4.29$)$ 甲 \\
\hline \multicolumn{7}{|l|}{ Education (vs 4-year college/postgraduate studies) } \\
\hline Non-married vs married/committed relationship & 1.00 (ref) & $1.86(1.63$ to 2.12$) \ddagger$ & 1.00 (ref) & 1.98 (1.72 to 2.27$) \ddagger$ & 1.00 (ref) & $1.32(1.07$ to 1.65$)$ q \\
\hline \multicolumn{7}{|l|}{ With whom you live (vs spouse/domestic partner) } \\
\hline Family & 1.00 (ref) & $1.96(1.51$ to 2.53$) \ddagger$ & 1.00 (ref) & $2.12(1.63$ to 2.74$) \ddagger$ & 1.00 (ref) & $1.40(0.90$ to 2.18$)$ \\
\hline Alone & 1.00 (ref) & 1.57 (1.35 to 1.82$) \ddagger$ & 1.00 (ref) & $1.63(1.40$ to 1.90$) \ddagger$ & 1.00 (ref) & $1.23(0.97$ to 1.57$)$ \\
\hline $\begin{array}{l}\text { Have assistance for home care from family, friends or } \\
\text { others, if needed (no vs yes) }\end{array}$ & 1.00 (ref) & $0.76(0.68$ to 0.86$) \ddagger$ & 1.00 (ref) & $0.76(0.67$ to 0.85$) \ddagger$ & 1.00 (ref) & $1.04(0.87$ to 1.24$)$ \\
\hline \multicolumn{7}{|l|}{$70-79$ year olds } \\
\hline Ever smokers & 1.00 (ref) & $1.41(1.24$ to 1.61$) \ddagger$ & 1.00 (ref) & $1.52(1.32$ to 1.74$) \ddagger$ & 1.00 (ref) & $1.51(1.23$ to 1.84$) \ddagger$ \\
\hline High school graduate or GED/some college & 1.00 (ref) & 1.49 (1.28 to 1.74$) \ddagger$ & $1.00(\mathrm{ref})$ & 1.45 (1.24 to 1.69$) \ddagger$ & 1.00 (ref) & $1.19(0.95$ to 1.50$)$ \\
\hline Non-married vs married/committed relationship & 1.00 (ref) & $1.76(1.53$ to 2.01$) \ddagger$ & 1.00 (ref) & $1.64(1.42$ to 1.91$) \ddagger$ & 1.00 (ref) & $1.34(1.08$ to 1.67$) \S$ \\
\hline \multicolumn{7}{|l|}{ With whom you live (vs spouse/domestic partner) } \\
\hline Family & 1.00 (ref) & 1.87 (1.36 to 2.57$) \ddagger$ & 1.00 (ref) & $1.82(1.32$ to 2.52$) \ddagger$ & 1.00 (ref) & $1.76(1.05$ to 2.94$)$ ? \\
\hline Alone & 1.00 (ref) & $1.52(1.32$ to 1.76$) \ddagger$ & 1.00 (ref) & $1.40(1.20$ to 1.63$) \ddagger$ & $1.00(\mathrm{ref})$ & $1.30(1.03$ to 1.64$)$ \% \\
\hline $\begin{array}{l}\text { Have assistance for home care from family, friends or } \\
\text { others, if needed (no vs yes) }\end{array}$ & 1.00 (ref) & $0.66(0.58$ to 0.76$) \ddagger$ & 1.00 (ref) & $0.67(0.58$ to 0.77$) \ddagger$ & 1.00 (ref) & 0.83 (0.68 to 1.02$)$ \\
\hline \multicolumn{7}{|l|}{ 80-89 year olds } \\
\hline Ever smokers & 1.00 (ref) & 1.14 (0.95 to 1.38$)$ & $1.00(\mathrm{ref})$ & 1.28 (1.05 to 1.56$) \ddagger$ & $1.00(\mathrm{ref})$ & $1.06(0.80$ to 1.40$)$ \\
\hline Ever felt the need to & 1.00 (ref) & $1.06(0.59$ to 1.90$)$ & 1.00 (ref) & $1.24(0.68$ to 2.26$)$ & 1.00 (ref) & 0.78 (0.32 to 1.93$)$ \\
\hline $\begin{array}{l}\text { Relatives/friends worry or complain about your alcohol } \\
\text { consumption }\end{array}$ & 1.00 (ref) & $1.46(0.49$ to 4.37$)$ & 1.00 (ref) & $1.67(0.55$ to 5.05$)$ & 1.00 (ref) & $0.57(0.13$ to 2.44$)$ \\
\hline \multicolumn{7}{|l|}{ Education (vs 4-year college/postgraduate studies) } \\
\hline Less than high school & 1.00 (ref) & 1.80 (1.35 to 2.40$) \ddagger$ & 1.00 (ref) & 1.77 (1.33 to 2.37$) \ddagger$ & 1.00 (ref) & $1.19(0.78$ to 1.80$)$ \\
\hline
\end{tabular}




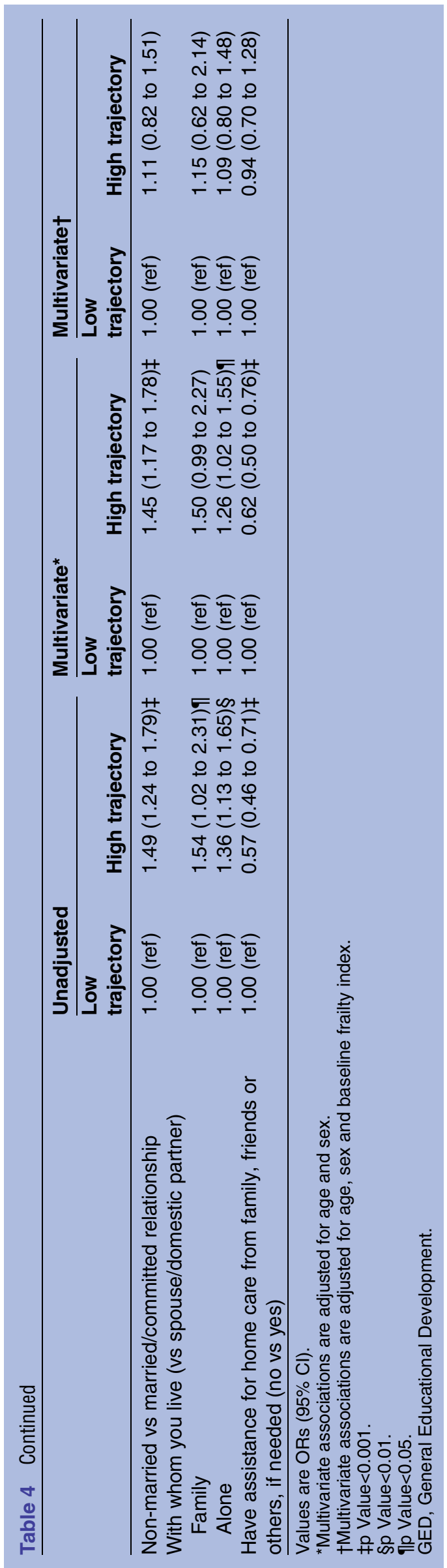

not available and others may not have been optimally measured. For example, education was assessed as a categorical variable which limited our ability to determine if a gradient or threshold effect was apparent for the association of years of education with frailty trajectories. In addition, our questions about alcohol consumption may have only identified individuals with excessive consumption and alcoholism. We did not have information to quantify the amount of drinking in all individuals to identify other patterns of drinking. Finally, while we clustered individuals by their long-term frailty trajectories, it is difficult to distinguish between rapid changes in frailty before death and changes related to the aging process.

Despite the aforementioned limitations, our study was population-based and included a large number of elderly patients. We were able to model longitudinal changes in frailty over an 8-year period and determine predictors of high frailty trajectories instead of relying on only one measure of frailty. Importantly, we observed that social and behavioural factors are associated with longitudinal changes in frailty over time, even after taking into account baseline frailty.

\section{CONCLUSION}

Social and behavioural factors were associated with a higher frailty trajectory over time. These associations varied across age, with stronger associations in younger ages. Less than a high school education, non-married marital status, smoking and concerns about alcohol consumption in those aged 60-79, and with whom you live in those aged 70-79 were predictive of being in the high frailty trajectory even after adjustment for baseline frailty. Social and behavioural factors associated with increasing frailty may offer a way to target interventions for ageing individuals at risk of worsening frailty, specifically when targeted at younger individuals.

Contributors AMC, LJFR and JLSS designed the study. LJFR and JLSS provided funding. AMC, DJJ and CF analysed the data. AMC, LJFR, JLSS and DJJ drafted the manuscript. All authors provided critical revisions of the manuscript.

Funding This work was supported by the Mayo Clinic Robert D and Patricia $E$ Kern Center for the Science of Health Care Delivery and was made possible using the resources of the Rochester Epidemiology Project, which is supported by the National Institute on Aging of the National Institutes of Health under Award Number R01AG034676.

Competing interests AMC, JLSS and LJFR are co-investigators on the Rochester Epidemiology Project (NIA AG034676).

Patient consent This study was considered minimal risk by the Institutional Review Boards; therefore, the requirement for informed consent was waived. Records of any patient who did not provide authorization for their medical records to be used for research, as per Minnesota statute (Statute 144.335), were not included.

Ethics approval Institutional Review Board.

Provenance and peer review Not commissioned; externally peer reviewed.

Data sharing statement No additional data are available. 
Open Access This is an Open Access article distributed in accordance with the Creative Commons Attribution Non Commercial (CC BY-NC 4.0) license, which permits others to distribute, remix, adapt, build upon this work noncommercially, and license their derivative works on different terms, provided the original work is properly cited and the use is non-commercial. See: http:// creativecommons.org/licenses/by-nc/4.0/

\section{REFERENCES}

1. Centers for Disease Control and Prevention. The state of aging and health in America 2013. Atlanta, GA: Centers for Disease Control and Prevention, US Department of Health and Human Services, 2013.

2. Ortman JM, Velkoff VA, Hogan H. An aging nation: the older population in the United States. Current Population Reports. Washington DC: U.S. Census Bureau, 2014:25-1140.

3. Rockwood K, Song X, Mitnitski A. Changes in relative fitness and frailty across the adult lifespan: evidence from the Canadian National Population Health Survey. CMAJ 2011;183:E487-94.

4. Abellan van Kan $\mathrm{G}$, Rolland $\mathrm{Y}$, Bergman $\mathrm{H}$, et al. The I.A.N.A Task Force on frailty assessment of older people in clinical practice. $J$ Nutr Health Aging 2008;12:29-37.

5. Chen X, Mao G, Leng SX. Frailty syndrome: an overview. Clin Interv Aging 2014;9:433-41.

6. Clegg A, Young J, Iliffe S, et al. Frailty in elderly people. Lancet 2013;381:752-62.

7. Morley JE, Vellas B, van Kan GA, et al. Frailty consensus: a call to action. J Am Med Dir Assoc 2013;14:392-7.

8. Buchman AS, Wilson RS, Bienias JL, et al. Change in frailty and risk of death in older persons. Exp Aging Res 2009;35:61-82.

9. Chamberlain AM, Finney Rutten LJ, Manemann SM, et al. Frailty trajectories in an elderly population-based cohort. J Am Geriatr Soc 2016;64:285-92.

10. Mitnitski A, Song X, Rockwood K. Trajectories of changes over twelve years in the health status of Canadians from late middle age. Exp Gerontol 2012:47:893-9.

11. Alvarado BE, Zunzunegui MV, Beland F, et al. Life course social and health conditions linked to frailty in Latin American older men and women. J Gerontol A Biol Sci Med Sci 2008;63:1399-406.

12. Avila-Funes JA, Helmer $\mathrm{C}$, Amieva $\mathrm{H}$, et al. Frailty among community-dwelling elderly people in France: the three-city study. J Gerontol A Biol Sci Med Sci 2008;63:1089-96.

13. Coelho T, Paul C, Gobbens RJ, et al. Determinants of frailty: the added value of assessing medication. Front Aging Neurosci 2015;7:56.

14. Cramm JM, Nieboer AP. Relationships between frailty, neighborhood security, social cohesion and sense of belonging among community-dwelling older people. Geriatr Gerontol Int 2013;13:759-63.

15. Fried LP, Tangen CM, Walston J, et al. Frailty in older adults: evidence for a phenotype. J Gerontol A Biol Sci Med Sci 2001;56: M146-56.

16. Gobbens RJ, van Assen MA, Luijkx KG, et al. Determinants of frailty. J Am Med Dir Assoc 2010;11:356-64.

17. Jurschik $P$, Nunin $C$, Botigue $T$, et al. Prevalence of frailty and factors associated with frailty in the elderly population of Lleida, Spain: the FRALLE survey. Arch Gerontol Geriatr 2012;55:625-31.

18. Lang IA, Hubbard RE, Andrew MK, et al. Neighborhood deprivation, individual socioeconomic status, and frailty in older adults. J Am Geriatr Soc 2009;57:1776-80.

19. Romero-Ortuno R. Frailty Index in Europeans: association with determinants of health. Geriatr Gerontol Int 2014:14:420-9.

20. Syddall H, Roberts HC, Evandrou M, et al. Prevalence and correlates of frailty among community-dwelling older men and women: findings from the Hertfordshire Cohort Study. Age Ageing 2010;39:197-203.

21. Szanton SL, Seplaki CL, Thorpe RJ Jr, et al. Socioeconomic status is associated with frailty: the Women's Health and Aging Studies. $J$ Epidemiol Community Health 2010;64:63-7.
22. Woo J, Leung J, Morley JE. Comparison of frailty indicators based on clinical phenotype and the multiple deficit approach in predicting mortality and physical limitation. J Am Geriatr Soc 2012;60:1478-86.

23. Woods NF, LaCroix AZ, Gray SL, et al. Frailty: emergence and consequences in women aged 65 and older in the Women's Health Initiative Observational Study. J Am Geriatr Soc 2005:53:1321-30.

24. Espinoza SE, Jung I, Hazuda H. Frailty transitions in the San Antonio Longitudinal Study of Aging. J Am Geriatr Soc 2012;60:652-60.

25. Etman A, Burdorf A, Van der Cammen TJ, et al. Socio-demographic determinants of worsening in frailty among community-dwelling older people in 11 European countries. J Epidemiol Community Health 2012;66:1116-21

26. Etman A, Kamphuis CBM, van der Cammen TJM, et al. Do lifestyle, health and social participation mediate educational inequalities in frailty worsening? Eur J Public Health 2015;25:345-50.

27. Lee JS, Auyeung TW, Leung J, et al. Transitions in frailty states among community-living older adults and their associated factors. J Am Med Dir Assoc 2014;15:281-6.

28. Hoogendijk EO, van Hout HP, Heymans MW, et al. Explaining the association between educational level and frailty in older adults: results from a 13-year longitudinal study in the Netherlands. Ann Epidemiol 2014;24:538-44.e2.

29. Hsu H-C, Chang W-C. Trajectories of frailty and related factors of the older people in Taiwan. Exp Aging Res 2015;41:104-14.

30. Rocca WA, Yawn BP, St Sauver JL, et al. History of the Rochester Epidemiology Project: half a century of medical records linkage in a US population. Mayo Clin Proc 2012;87:1202-13.

31. St. Sauver JL, Grossardt BR, Leibson CL, et al. Generalizability of epidemiological findings and public health decisions: an illustration from the Rochester Epidemiology Project. Mayo Clin Proc 2012;87:151-60.

32. St. Sauver JL, Grossardt BR, Yawn BP, et al. Use of a medical records linkage system to enumerate a dynamic population over time: the Rochester Epidemiology Project. Am J Epidemiol 2011:173:1059-68.

33. St. Sauver JL, Grossardt BR, Yawn BP, et al. Data resource profile: the Rochester Epidemiology Project (REP) medical records-linkage system. Int J Epidemiol 2012;41:1614-24.

34. Rockwood K, Andrew M, Mitnitski A. A comparison of two approaches to measuring frailty in elderly people. J Gerontol A Biol Sci Med Sci 2007;62:738-43.

35. Searle SD, Mitnitski A, Gahbauer EA, et al. A standard procedure for creating a frailty index. BMC Geriatr 2008;8:24.

36. Kulminski AM, Ukraintseva SV, Kulminskaya IV, et al. Cumulative deficits better characterize susceptibility to death in elderly people than phenotypic frailty: lessons from the Cardiovascular Health Study. J Am Geriatr Soc 2008;56:898-903.

37. McNallan SM, Chamberlain AM, Gerber Y, et al. Measuring frailty in heart failure: a community perspective. Am Heart J 2013;166:768-74.

38. Clegg A, Bates C, Young J, et al. Development and validation of an electronic frailty index using routine primary care electronic health record data. Age Ageing 2016;45:353-60.

39. Goodman RA, Posner SF, Huang ES, et al. Defining and measuring chronic conditions: imperatives for research, policy, program, and practice. Prev Chronic Dis 2013;10:E66.

40. US Department of Health and Human Services. Multiple chronic conditions-a strategic framework: optimum health and quality of life for individuals with multiple chronic conditions. Washington DC, 2010

41. Rocca WA, Boyd CM, Grossardt BR, et al. Prevalence of multimorbidity in a geographically defined American population: patterns by age, sex, and race/ethnicity. Mayo Clin Proc 2014;89:1336-49.

42. Genolini C, Falissard B. KmL: a package to cluster longitudinal data Comput Methods Programs Biomed 2011;104:e112-21.

43. Mello Ade C, Engstrom EM, Alves LC. Health-related and socio-demographic factors associated with frailty in the elderly: a systematic literature review. Cad Saude Publica 2014;30:1143-68. 